\title{
Commentary: Engaging the Majority World in Research on Adolescence
}

\author{
Anne C. Petersen \\ University of Michigan and Global Philanthropy Alliance
}

The special issue of the Journal of Research on Adolescence (JRA) focused on Majority World adolescents is both timely and important. As identified in the editors' introduction, the current body of scholarship on adolescence published in English-language journals is overwhelmingly based on Minority World samples and theories (Raffaelli, Lazarevic, Koller, Nsamenang, \& Sharma, 2012). There is an increasing research being performed in the Majority World, yet there are serious barriers to publishing findings in Minority World journals, and there are few Majority World journals.

It is also appropriate that $J R A$ would play a leadership role with this special issue. As the editors note, the Society for Research on Adolescence (SRA) has from the beginning (e.g., the article published by three early SRA presidents: Dornbusch, Petersen, \& Hetherington, 1991) positioned the organization to be a leader of research on adolescence. Given that all science is now global (e.g., Suresh, 2012), developmental science on adolescence must be global. Further, the phenomena of adolescence especially require cultural and contextual grounding because of the nature of the developmental period spanning childhood to adulthood. And as the editors note, young people in the second decade of life constitute as much as $23 \%$ of major regional populations globally, and adolescents in the Majority World are $88 \%$ of the total globally. It is a global priority to understand adolescents, and find effective ways to help them reach a productive adulthood as evidenced by the remarkable decision by the World Bank to focus their annual development report on youth (World Bank, 2007.)

The fifteen articles in this special issue represent a highly diverse group, by topic and region. Each focuses on a sample of adolescents in the Majority World, in a few cases with comparison samples from the Minority World. Five major world regions are represented: Asia (seven articles), Africa (Sub Saharan) and Latin America/Caribbean Islands

\footnotetext{
Requests for reprints should be sent to Anne C. Petersen, Center for Human Growth and Development, University of Michigan, 300 North Ingalls, 10th Floor, Ann Arbor, MI 48109-5406. E-mail: annepete@umich.edu
}

(each five articles), United States and Canada (four), and Europe (one). The articles focus on many different topics and use diverse methods. Diverse disciplinary perspectives enrich the collection. Only two articles employed more than one time of measurement, although many were developmental in concept.

The goal for the special issue was to build on existing descriptive research (first generation) with a second generation of studies that provide an international perspective on adolescent development. Specifically, the call requested papers that (1) evaluated/expanded fundamental models of development, (2) described successful models of intervention to improve the well-being of youth, or (3) studied the impact of global restructuring or the shifting balance of power on the experiences of young people, as well as of current global influences. By the editors' count, they published nine papers in group $1(60 \%)$, and three each in groups 2 and 3. The topics identified by the editors were challenging and designed to advance the field. Fewer papers addressed topics 2 and 3, with globalization impacts the most difficult to address, from this commentator's perspective.

Based on my experience with an international scientific society - the International Society for the Study of Behavioral Development (ISSBD) - and with a global philanthropy making grants to youth in Africa (Global Philanthropy Alliance), having more data or even more knowledge on the Majority World is necessary but not sufficient as a goal. To have a global science of adolescence, it is necessary to have a global body of researchers conducting research on adolescence. Research collaboration is an excellent way to build capacity of researchers from Majority World countries, and most of the papers in this special issue appear to be doing that, based on information on the authors and their institutions: $87 \%$ of the articles include authors either at institutions in the countries sampled or authors appear to represent ethnicity of the samples.

(C) 2013 The Author

Journal of Research on Adolescence (C) 2013 Society for Research on Adolescence DOI: $10.1111 /$ jora. 12010 
Notably, two first authors' institutions represent the country sampled.

Those who engage in Majority-Minority World collaborations report increased learning and understanding, based on my experience. But good intentions are not enough. It is extremely important to engage collaborations with mutual respect, mutual interest, mutual responsibility, and mutual benefit. Those involved with this special issue appear to have moved beyond research as an "extractive" exercise of data collection in Majority World countries to engage at least mutual learning.

It is important to recognize that many researchers and universities in the Majority World have limited research infrastructure requiring special attention from the Minority World. For example, Yankah (2012) documented the common challenges of doctoral students and researchers in African universities. Internet connectivity and even power may be unreliable, library resources are limited, and faculty members have limited time and resources. Even after a couple of decades collaborating internationally, I am still learning about the challenges. Yet I continue to be impressed with the high motivation and intelligence of colleagues from the Majority World, and their rapid uptake of opportunity. I believe that knowledge will expand enormously if we can unleash the available talent and find ways to engage all who wish to become researchers of adolescence. Based on my working experience with two of the editors of this special issue (Bame Nsamenang and Silvia Koller), among other colleagues, I expect fresh perspectives, new insights, and important research results.

This special issue is an outstanding step toward developing a global knowledge base that includes not only Majority World data but also engages Majority World research colleagues. The latter step is key for a sustainable knowledge base on global adolescence.

\section{REFERENCES}

Dornbusch, S. M., Petersen, A. C., \& Hetherington, E. M. (1991). Predicting the future of research on adolescence. Journal of Research on Adolescence, 1, 7-17.

Raffaelli, M., Lazarevic, V., Koller, S. H., Nsamenang, A. B., \& Sharma, D. (2012). Introduction: Special issue on adolescents in the Majority World. Journal of Research on Adolescence, 23, 1-8.

Suresh, S. (2012). Cultivating global science. Science, 336, 959.

World Bank. (2007). World bank development report 2007. Retrieved July 14, 2010, from http://go.worldbank.org/AR3D4L0E40

Yankah, K. (2012). Towards building a global research community in higher education. Keynote address at UMAPS final dinner, University of Michigan. Retrieved July 14, 2010, from http://www.ii.umich.edu/asc/ aboutus/newsletters/winter2012newsletter/perception isreallyimportant_ci. Presentation manuscript is also available from author. 